\title{
Physicians disagree on legal age for cannabis
}

\author{
Cite as: CMAJ 2017 January 30;189:E174-5. doi: 10.1503/cmaj.1095378
}

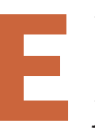
ighteen or twenty-one? As Canada moves closer to legalizing marijuana, two physician associations disagree on the right legal age to buy and smoke the drug.

The Task Force on Cannabis Legalization and Regulation's framework report advocates for a Canada-wide legal age of 18 , leaving it to provinces and territories to set a higher age if they like.

Eighteen is too early, maintains the Canadian Medical Association (CMA), which is adamant the age be 21 years. Medical evidence indicates marijuana is detrimental to development of the human brain, a process that doesn't stop until the mid-20s.

"In a perfect world what we would recommend based solely on the scientific evidence is an age of legalization of 25," said Dr. Jeff Blackmer, CMA vice president of medical professionalism.

A study in the Journal of the International Neuropsychology Society reported that "even after a month of monitored abstinence, adolescent marijuana users demonstrate subtle neuropsychological deficits compared with nonusers."

Another study, published in Psychopharmacology in 2014, supported by the United States National Institute of Drug Abuse, found that "early onset of [marijuana] use negatively impacts white matter development and is associated with behavioural impulsivity, a combination that may have enduring negative effects, particularly on the developing brain."

Restricting use to an older age, says Blackmer, also helps to "prevent young people having to go to black market and illicit sources, and all the issues with contamination with fentanyl." After assessing the available evidence, CMA recommended a mid-range limit of 21 .

The Canadian Paediatric Society (CPS), on the other hand, agrees with the

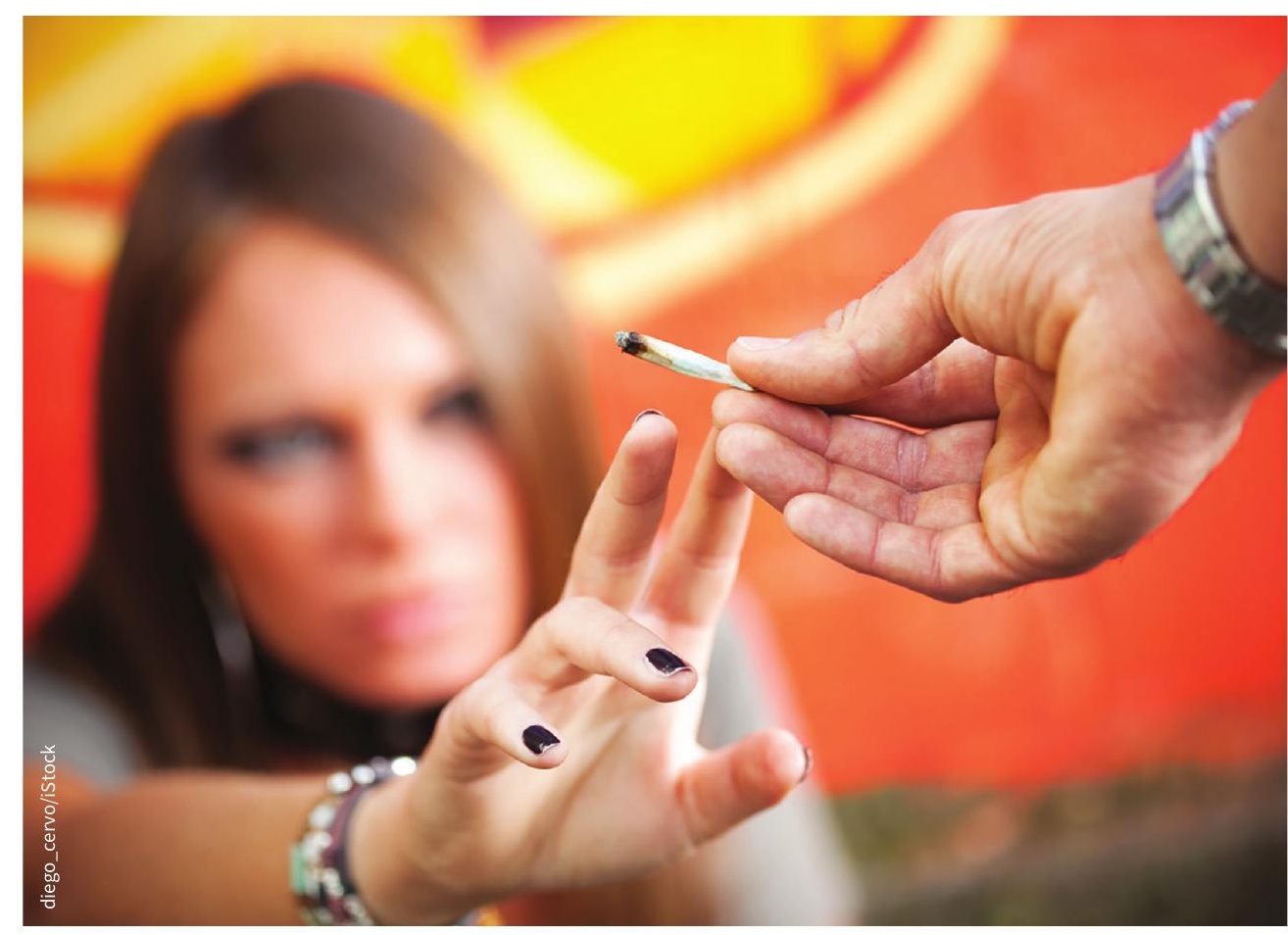

Medical evidence indicates marijuana is detrimental to development of the human brain, a process that doesn't stop until the mid-20s.

age limit suggested by the task force. "Yes, 21 based on the brain studies is better than 18," said Dr. Christina Grant, part of the CPS adolescent health committee, which coauthored a study that looked at potential harm to youth. "But the actual brain studies don't delineate at what age the risk trade off would actually be best. And what about all the youths using anyways?"

Canada ranked the highest among 29 developed nations for cannabis use in children aged 11-15, according to a 2013 UNICEF report. More recently, in 2015, a survey from the Centre for Addiction and Mental Health indicated that $21.3 \%$ of students from grade 7-12 used marijuana. Young adults aged $20-24$ are 2.5 times more likely to smoke cannabis than those 25 or older, according to the 2013
Canadian Tobacco, Alcohol and Drugs Survey.

"They're the biggest users and they're the most vulnerable," Grant said of the 20-24 age group. "So, just by limiting to 21 , they're still going to use it. But if it's regulated, if there are disincentives like the taxes and increased costs for the highest potency, that's positive."

In addition to pricing disincentives, the federal task force recommends keeping dispensaries away from schools and ensuring that smoke-free laws apply to cannabis to mitigate the effects of second-hand smoke. It also suggests that cannabis packaging be mandated to use plain labels that detail potency, and strain of plant.

Grant said the CPS was happy with many of the task force's recommendations, including measures to curb driving 
under the influence of the drug and a ban on edible forms of marijuana - including candies - which have led to accidental overdose by toddlers in the US.

It's now up to the "legislative process to decide what parts of their report and what recommendations will be implemented and which ones will not," said Blackmer. "We think they've done a really good job of getting things started."
Medical groups aren't the only ones opining on the correct legal age. On Dec.15, Prime Minister Justin Trudeau told the press that he thought marijuana should be available to people at the same age they can legally drink alcohol, which is either 18 or 19 , depending upon where they live in Canada. His comment came just two days after the task force recommended 18 years of age.
The government has vowed to legalize the drug, which has been on the list of prohibited substances since 1923, in the spring of 2017. While the country waits on legalization, police can still lay criminal charges for possession, as well as for selling without a Health Canada license for medical marijuana.

Jay Rankin, CMAJ 